\title{
Cranial Defects in the Goldenhar Syndrome
}

\author{
Golder N. Wilson \\ Department of Pediatrics and Communicable Diseases, Mott Children's Hospital, \\ The University of Michigan, Ann Arbor
}

\begin{abstract}
Four patients are presented with the Goldenhar syndrome (GS) and cranial defects consisting of plagiocephaly, microcephaly, skull defects, or intracranial dermoid cysts. Twelve cases from the literature add hydrocephalus, encephalocele, and arhinencephaly to a growing list of brain anomalies in GS. As a group, these patients emphasize the variability of GS and the increased risk for developmental retardation with multiple, severe, or unusual manifestations. The temporal relation of proposed teratogenic events in GS provides an opportunity to reconstruct biological relationships within the 3-5-week human embryo.
\end{abstract}

Key words: Goldenhar syndrome, cranial defects, oculoauriculovertebral “dysplasia”, mandibulofacial dysostosis, hemifacial microsomia

\section{INTRODUCTION}

Since the description of three patients with epibulbar dermoids, preauricular appendages, and mandibular hypoplasia [Goldenhar, 1952], the variety and variability of anomalies associated with Goldenhar syndrome (GS) have been increasingly appreciated [Setzer et al, 1981]. Gorlin et al [1963] added vertebral defects to the spectrum of anomalies in GS, while others [Opitz and Faith, 1969; Greenwood et al, 1974; Feingold and Baum, 1978] have reported diverse ocular, skeletal, cardiac, and visceral defects. Because of the sporadic and heterogenous nature of GS, the prognosis of affected patients must be individually established by the anticipation and documentation of component anomalies. My purpose here is to review patients with GS and cranial defects and to emphasize the importance of cranial evaluation for selected GS patients. This report was stimulated by two GS patients with intracranial dermoids (cases 1 and 2) whose clinical course was more severe than originally predicted.

Received for publication November 19, 1981; revision received May 20, 1982.

Address reprint requests to Dr. Golder N. Wilson, K2015 Holden, University of Michigan Hospitals, Ann Arbor, MI 48109. 
An issue that complicates understanding of GS is its unclear relationship to more isolated forms of lateral facial dysplasia [Grabb, 1965; Ross, 1975], including hemifacial microsomia [Pashayan et al, 1970; Cohen, 1971; Thomas, 1980]. Isolated hemifacial microsomia can be viewed as a malformation [Spranger et al, 1982] involving the first and second branchial arches. However, when part of a malformation syndrome, hemifacial microsomia may be seen with the same variable pattern of ocular, cardiac, renal, radial, and vertebral anomalies described for GS. I therefore include in this series of cranial defects any patient having characteristic auricular plus mandibular or ocular defects that cannot be explained as unilateral malformation. Recognized Mendelian [Herrmann and Opitz, 1969; Summitt, 1969] or chromosomal disorders [Hodes et al, 1981] involving branchial arch defects are excluded.The series comprises four patients from a total of eight GS patients observed by our pediatric genetics service over the past $5 \mathrm{yr}$ and 12 case reports gathered by survey of literature published after 1952 .

\section{CLINICAL REPORT}

\section{Patient 1}

The patient was a $2.2 \mathrm{~kg}$ girl born $36 \mathrm{wk}$ after an uncomplicated pregnancy to a gravida 125 -year-old white woman. The family history was unremarkable. Examination (Fig. 1A,B) showed plagiocephaly, right hemifacial microsomia, bilateral cleft of lip and palate, micrognathia, hypoplastic and malformed right ear, preauricular

A
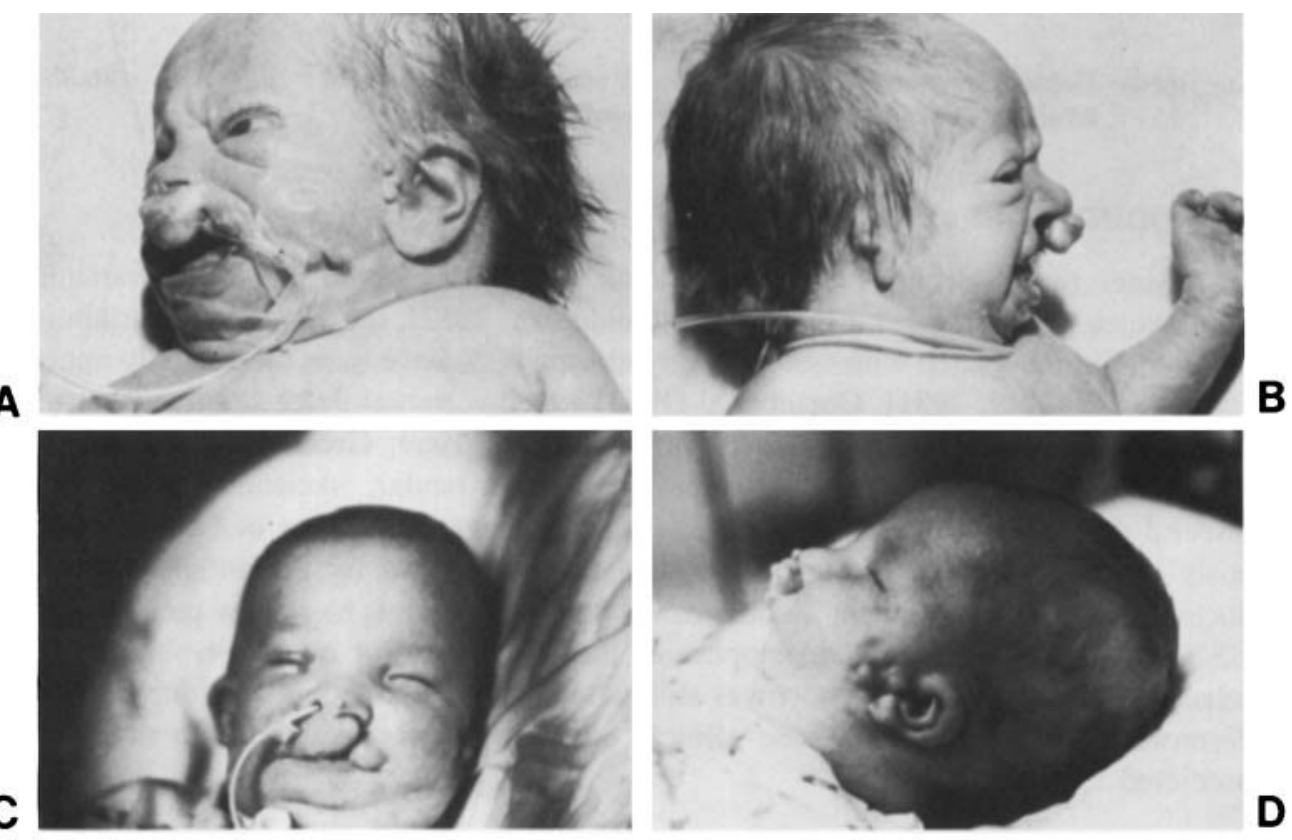

Fig. 1. (A) Patient 1, the left frontal view shows skin tags on the cheek and chest and a hypoplastic tragus; (B) patient 1, right lateral view; the apparent mass posterior to the neck is a skin fold; (C) patient 2 , the frontal view shows a skin tag on the nose, cleft lip, and malformed ears; (D) patient 2 , left lateral view. 
and anterior cervical cartilaginous tags bilaterally, absence of right external auditory meatus, a lipoepidermoid cyst in the lower outer quadrant, a coloboma of the outer upper lid on the left, and absence of the left thumb. Skull films showed occipital intracranial calcification and chest roentgenograms demonstrated dextrocardia, hemivertebrae at T5-T7, scoliosis, and corresponding rib anomalies. CT scan showed cerebellar hypoplasia with a mass interpreted as a lipoepidermoid cyst of the posterior corpus callosum (Fig. 2A). She had a normal 46, XX chromosome constitution. She had neonatal feeding problems, failure to thrive, and chronic keratitis requiring bilateral tarsorrhaphy. Repair of the lip and palate clefts failed several times owing to

A
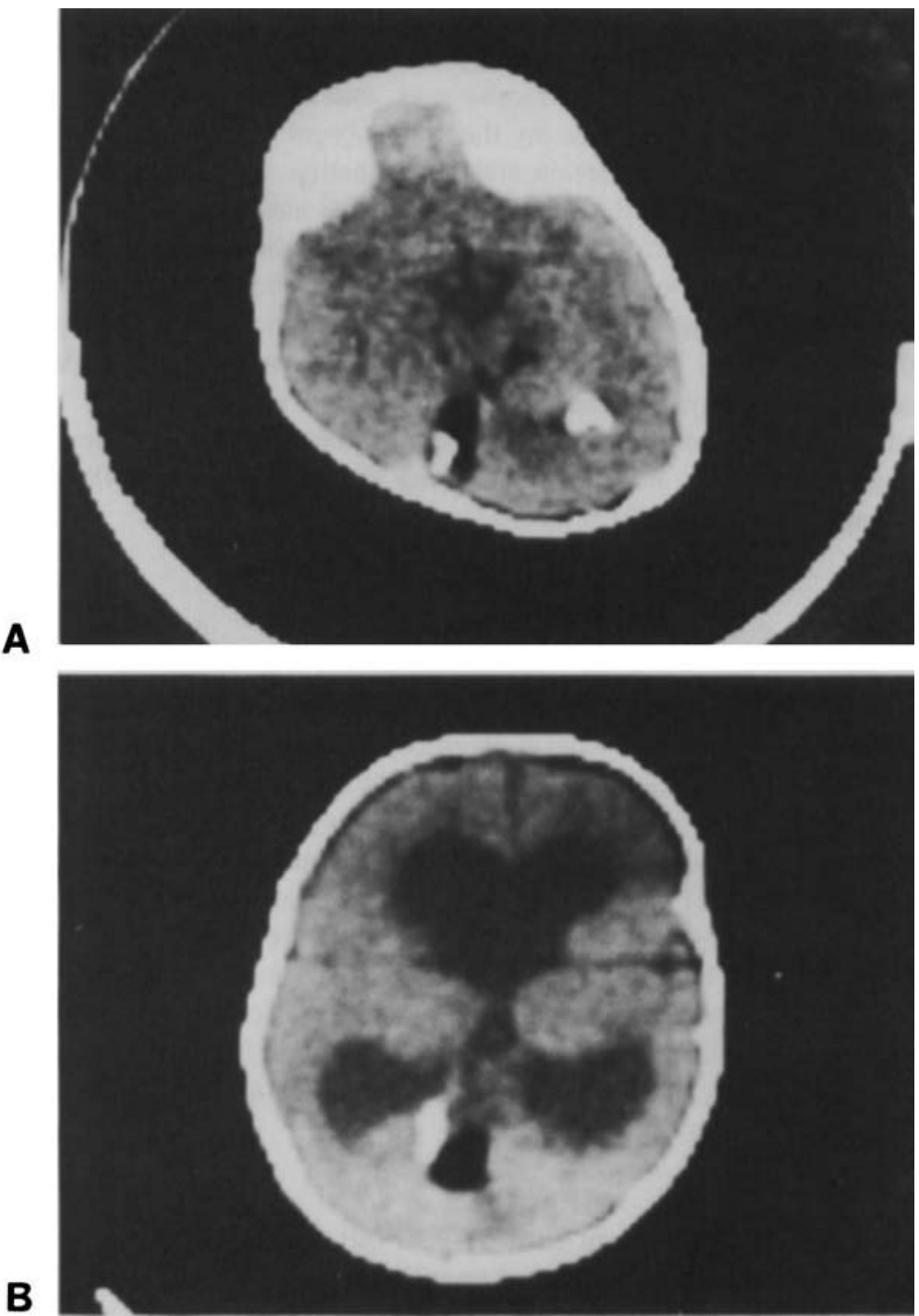

Fig. 2. CT Scans of patient 1(A) and patient 2(B) showing occipital masses with densities characteristic of fat and bone. 
poor healing, but was eventually successful. A hearing loss was documented and treated with hearing aid. At 17 mo the girl had a length, occipitofrontal head circumference (OFC), and developmental level appropriate for five months and a weight appropriate for 2 mo. Results of repeat CT scan were unchanged.

\section{Patient 2}

The patient was born at 36 wk to a 25 -year-old gravida 3 , para 2 white woman with micrognathia, microcephaly, and a mild mental retardation. The family history was otherwise unremarkable. Vaginal delivery followed third trimester polyhydramnios and prolonged rupture of membranes, yielding a severely depressed (Apgars 0 and 1) male infant weighing $2,000 \mathrm{gm}$. Neonatally the infant had hyaline membrane disease, hyperbilirubinemia, and seizures. At $10 \mathrm{wk}$, the OFC was $35 \mathrm{~cm}$, length 54 $\mathrm{cm}$, and weight $4,100 \mathrm{gm}$. There was a right anophthalmia, left cleft lip and cleft palate, bilateral malformed ears, preauricular tags, and a nasal tag (Fig. 1C,D). The external auditory meatus was small on the left, absent on the right. Additional malformations were left choanal atresia and micrognathia. Roentgenograms showed asymmetric calvaria, hypoplastic left mandibular ramus, and intracranial calcification in the occipital region. CT scan (Fig. 2B) showed dilated ventricles, hypoplastic septum pellucidum, partially calcified, and partially fatty lesion in the left posterior hemisphere. The dilated ventricles ascribed to midline hypoplasia of the brain have not enlarged further. EEG was consistent with diffuse neuronal disturbance and underlying seizure tendency. Ophthalmology evaluation showed no eye tissue OD and microphthalmia OS. A mild hearing loss was demonstrated. The patient tolerated repair of the cleft lip and is now growing along the 10 th centile at 18 mo with a developmental age of about 10 mo.

\section{Patient 3}

The patient was born at 41 wk to a 17 -year-old gravida 2, para 1 white woman. The family history was unremarkable. The gestation was complicated by polyhydramnios, and the infant required resuscitation. Birth weight was $3.22 \mathrm{~kg}$. On examination at 2 days the infant was found to have plagiocephaly, left hemifacial microsomia, OFC of $34.5 \mathrm{~cm}$, a medial coloboma of the upper lid and a lipoepidermoid cyst in the lower outer quadrant OS, a small right ear, lobular remnant of left ear with preauricular tags, a left cleft lip and cleft palate, severe micrognathia, bifid right thumb, left simian crease, Tetralogy of Fallot, left mandibular and maxillary hypoplasia on skull films, hemivertebrae at T3-4, hearing loss, and normal chromosomes. The infant had recurrent aspiration pneumonia, chronic atelectasis and gastroesophageal reflux managed by tracheostomy, and Nissen fundoplication. He also had a Blalock-Taussig shunt. Repair of the cleft lip and palate was not successful. At 2 yr the patient had a physical size and developmental level appropriate for $6 \mathrm{mo}$. He died at $3 \mathrm{yr}$ of pneumonia. No autopsy was obtained.

\section{Patient 4}

The patient was born at term to a 31-year-old gravida 3, para 1, abortus 1 oriental mother who had severe nausea and vomiting during her pregnancy. Doxylamine succinate was taken throughout the pregnancy. Delivery and family history were unremarkable. Birthweight was $2.9 \mathrm{~kg}$. Neonatally, the infant had hyperbilirubinemia, 
feeding problems, reflux vomiting, dehydration, lethargy, weight loss, and Escherichia coli septicemia. At $6 \mathrm{wk}$ he weighed $2.78 \mathrm{~kg}$, with disproportionate microcephaly, a small anterior fontanel with overlapping sutures, abnormal posturing, hyperreflexia, prominent lateral ventricles, slight deficiency of frontal lobe white matter, a prominent pontine cistern on CT scan, and severe disorganization of EEG pattern. Brain stem auditory evoked responses showed normal cortical transmission by bone, but none by air. Congenital hip dislocation was treated by Pavlik harness.

At $6 \mathrm{mo}$ he had a weight of $5.8 \mathrm{~kg}$, length of $66.5 \mathrm{~cm}$, and OFC of $40 \mathrm{~cm}$. The head was asymmetric and brachycephalic with hypoplasia and indentation of the buccinator and parotid regions. The ears were small and posteriorly angulated with simple conchae and malformed helices. There was micrognathia and a cleft of the posterior soft palate. Other anomalies included right simian crease, a hemangioma on the dorsum of the left hand, a deep pilonidal sinus, a left horseshoe kidney with duplication of collecting system, and a "butterfly" vertebra at T5. The hearing loss was confirmed and treated with hearing aid. Gastroesophageal reflux was demonstrated and corrected surgically. At 18 mo has a developmental age of about 10 mo.

\section{RESULTS}

Table I summarizes the manifestations of our cases and compares them with those of other previously reported Goldenhar syndrome (GS) cases with cranial defects. The intracranial dermoid cysts in patients 1 and 2 were the most unusual findings. On skull films these masses contained calcium that surrounded a fatty center demonstrated on CT scans (Fig. 2). This appearance was similar to that of the dermoid tumor demonstrated in a 28-year-old woman with GS by Murphy et al [1980]. When the latter tumor was removed, it was shown to contain the stratified squamous epithelium and sebaceous gland typical of dermoid cysts.

Patients 1-4 were striking for the number and severity of their anomalies compared to most other cases of GS. All four had severe first and second branchial arch anomalies with cleft lip and palate, while patients 1, 3, and 4 had radial or vertebral malformations. Patients 1 and 4 had dextrocardia, patient 3 had Tetralogy of Fallot. These cardiac anomalies are characteristic of patients with GS [Greenwood et al, 1974]. Cases 1 and 2 had intrauterine growth retardation, and all four had severe failure to thrive presumably owing to swallowing and feeding difficulties.

Skull defects in previously reported GS patients include cranial asymmetry, hypoplasia of the petrous bone or ethmoid bones, platybasia, and absence of the internal auditory canal (Table I). Brain anomalies include hydrocephalus, ArnoldChiari malformation, unilateral arhinencephaly, and encephalocele. The occurrence of the latter anomaly in 2 patients in Table $I$ and 11 cases reported or cited by Cohen [1971] establishes encephalocele as a rare component of GS.

Striking findings in GS patients selected for cranial defects include male sex preponderance $(12 / 16)$, growth failure (5/5), facial asymmetry $(11 / 13)$, eye defects $(15 / 16)$, hearing deficit $(8 / 8)$, visceral defects $(7 / 15)$, and vertebral anomalies (11/ $16)$. Better documentation and reporting of these anomalies in severely affected GS patients will increase their usefulness as indicators of intellectual potential. The incidence of mental retardation in GS patients with cranial defects was $9 / 11(82 \%$, Table I). A series of GS patients selected by other criteria had a $25 \%$ [Feingold and 
TABLE I. Manifestations of Patients With Goldenhar Syndrome and Cranial Defects

\begin{tabular}{lccccccccccccc} 
Manifestations & \multicolumn{4}{c}{ Present cases } & & \multicolumn{4}{c}{ Cohen 1971} & & Shokeir [1977] & Kirkham [1971] \\
\cline { 2 - 7 } Sex-original & 1 & 2 & 3 & 4 & & 5 & 6 & 7 & 8 & 9 & 10 \\
case number & F & M & M & M & M-1 & M-2 & M-3 & M-4 & M-1 & M \\
\hline
\end{tabular}

Growth

Intrauterine growth

retardation

Failure to thrive

Orofacial

Facial asymmetry

Anopthalmia/

microphthalmia

Optic coloboma

Optic dermoid/

lipodermoid cyst

Malformed ears

Hearing deficit

Cleft lip/cleft palate

Micrognathia

Organs

Cardiac defect

Renal anomaly

Pulmonary

hypoplasia

Skeletal

Radial defect

Vertebral defect

Cranial

Mental retardation

Microcephaly

Cranial

asymmetry

Intracranial

dermoid

Encephalocele

Hydrocephalus

Skull defect

Miscellaneous$$
+^{\mathrm{g}}+{ }^{\mathrm{h}}-\mathrm{t}^{\mathrm{i}}-\mathrm{C}^{\mathrm{C}}-\mathrm{C}_{-}
$$

$\begin{array}{lllllllll}+\mathbf{a}+ & - & - & ? & - & ? & ? & ? & ? \\ + & + & + & + & ? & ? & ? & ? & ?\end{array}$

$+\quad+\quad+\quad+\quad+\quad$ ?

$-\quad+\quad-\quad+\quad+\quad+\quad+\quad+$

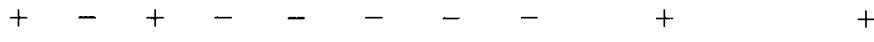

$+\quad-\quad+\quad-\quad-\quad-\quad-\quad-\quad+$

$++++++++$

$+\quad+\quad$ ? ? ? ? +

++++++ + + +

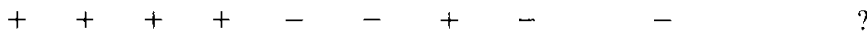

$+\quad+\quad+\quad-\quad-\quad-\quad-\quad+\quad+$

? - - ? ? ? ? ?

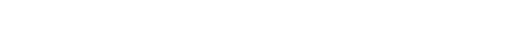$$
\begin{array}{llllllllll}
+ & - & + & - & - & - & - & - & - & - \\
+ & - & + & + & + & - & - & - & + & +
\end{array}
$$$$
+++++ \text { + }+ \text { ? ? }
$$$$
+\quad-+ \text { ? ? ? ? }
$$$$
++++++ \text { ? ? ? }
$$$$
+\quad+\quad-\quad-\quad-\quad-\quad-\quad \text { ? }
$$$$
\begin{array}{lllllllllll}
- & - & - & - & - & - & - & - & + & +
\end{array}
$$

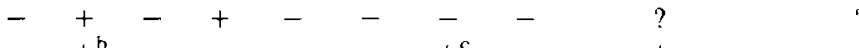

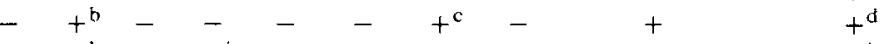

${ }^{a}$ Manifestation present $(+)$, manifestation not excluded (?), or manifestation absent $(-)$ by author's interpretation.

${ }^{b}$ Choanal atresia.

${ }^{c}$ Parietal osseous defect.

${ }^{d}$ Petrous bone hypoplasia, absent internal auditory canal.

ePlatybasia.

${ }^{f}$ Ethmoid hypoplasia

ECerebellar hypoplasia.

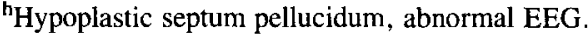

iFrontal lobe dysplasia, abnormal EEG.

${ }^{\mathrm{j}}$ Calcified anterior falx cerebri.

${ }^{\mathrm{k}}$ Arnold-Chiari malformation.

'Unilateral arhinencephaly.

mOccipital scalp defect. 


\begin{tabular}{|c|c|c|c|c|c|c|}
\hline $\begin{array}{c}\text { Gupta et } \\
\text { al [1968] } \\
11 \\
\text { M } \\
\end{array}$ & $\begin{array}{c}\text { Michaud and } \\
\text { Sheridan [1974] } \\
12 \\
\text { F } \\
\end{array}$ & $\begin{array}{c}\text { Lambda and } \\
\text { Ramamurthy [1973] } \\
13 \\
\text { M-2 }\end{array}$ & $\begin{array}{c}\text { Murphy et } \\
\text { al [1980] } \\
14 \\
\text { F }\end{array}$ & $\begin{array}{c}\text { Aleksic et } \\
\text { al }[1975] \\
15 \\
\text { F }\end{array}$ & $\begin{array}{c}\text { Smithells } \\
{[1964]} \\
16 \\
M\end{array}$ & $\begin{array}{c}\text { Incidence } \\
\text { (percent) } \\
12 \mathrm{M} 4 \mathrm{~F} \\
\end{array}$ \\
\hline$?$ & ? & $?$ & $?$ & $?$ & + & $3 / 7$ \\
\hline$?$ & + & $?$ & $?$ & $?$ & $?$ & $5 / 5(100)$ \\
\hline+ & - & + & + & + & $?$ & $11 / 13 \quad(85)$ \\
\hline- & - & + & - & + & $?$ & $8 / 15 \quad(53)$ \\
\hline- & + & - & + & $?$ & - & $6 / 15 \quad(40)$ \\
\hline+ & + & + & + & $?$ & + & $8 / 15 \quad(53)$ \\
\hline+ & + & + & + & + & + & $16 / 16(100)$ \\
\hline$?$ & $?$ & + & + & $?$ & $?$ & $8 / 8(100)$ \\
\hline- & - & - & - & + & - & $9 / 16 \quad(56)$ \\
\hline$?$ & $?$ & $?$ & $?$ & + & + & $7 / 11 \quad(64)$ \\
\hline$?$ & - & ? & - & + & t & $6 / 14 \quad(43)$ \\
\hline$?$ & - & $?$ & - & - & - & $1 / 8 \quad(13)$ \\
\hline- & - & $?$ & - & - & - & $1 / 15 \quad(6.7)$ \\
\hline- & - & - & - & - & - & $2 / 16 \quad(13)$ \\
\hline- & + & + & + & + & + & $11 / 16 \quad(69)$ \\
\hline$?$ & - & + & - & $?$ & $?$ & $9 / 11 \quad(82)$ \\
\hline - & - & $?$ & - & $?$ & ? & $3 / 7 \quad(43)$ \\
\hline+ & - & + & - & + & $?$ & $11 / 13 \quad(85)$ \\
\hline$?$ & $?$ & $?$ & + & - & $?$ & $3 / 10 \quad(30)$ \\
\hline+ & - & - & - & - & - & $2 / 16 \quad(13)$ \\
\hline+ & + & $?$ & + & - & $?$ & $5 / 12$ \\
\hline+ & $+{ }^{\circ}$ & - & - & $+{ }^{f}$ & $?$ & $7 / 15 \quad(47)$ \\
\hline- & $+^{k}$ & - & - & $t^{\prime}$ & $+^{\mathrm{m}}$ & $7 / 16 \quad(44)$ \\
\hline
\end{tabular}

Baum, 1978], 16.7\% [Shokeir, 1977], or 6\% [Hollowich and Verbeck, 1969] incidence of mental retardation. Clearly these are low estimates since many patients die or are lost to follow-up before intellectual function can be adequately assessed. Table I demonstrates that GS patients with multiple, severe, or unusual malformations face a higher risk for retardation than the 10-15\% quoted in textbooks [Gorlin et al, 1976].

\section{DISCUSSION}

This report and review of patients with GS and cranial defects emphasizes the broad spectrum of anomalies that can be anticipated. Table I includes defects of heart, lung, kidney, radial ray, and the brain in addition to malformations of eye, spine and branchial arch derivatives. Cohen's [1971] recommendation of skeletal survey in severely affected patients is further supported since the neurologic anomalies-microcephaly, cranial asymmetry, skull defects, hydrocephalus, and certain intracranial 
masses - may be documented or suspected on skull films. Abnomalities of cranial volume, shape, or calcification should then be defined by CT scan. Defects of the external or internal auditory canal demand early audiologic evaluation. The vigorous cardiorespiratory support and plastic surgery which GS patients often require should be undertaken only after parents and physicians appreciate the spectrum of defects and realistically appraise the patient's intellectual potential.

Cohen [1971], Michaud et al [1974], and Murphy et al [1980] have emphasized neurologic abnormalities in their patients. Cherstvoy et al [1978] also report four cases of GS with brain anomalies ("dysplasia" of the frontal lobe, internal capsule, lissencephaly) and normal chromosomes, but their patients were not described in sufficent detail for inclusion in this report. Table I is a first step towards a defined set of neurologic defects and developmental indicators in GS patients.

As described in patients with anterior encephalocele [Rapport et al, 1981], the cranial defects in GS represent a developmental disturbance of neuroectoderm (anophthalmia, frontal lobe hypoplasia, dermoid cysts) and cranial mesoderm (skull defects). The optic primordium and anterior neuropore are both present in the 24-day human embryo and their subsequent development is central to the development of facial structure [Rapport et al, 1981]. These cranial anomalies fit in with other GS defects in defining a similar period of dysmorphogenetic action. Formation of the branchial arches (malformed ears, micrognathia), ureteral bud (renal abnormalities), sclerotomes (vertebral malformations), limb buds (radial aplasia), and cardiac rotation (dextrocardia, transposition) also begin at 23-30 days of gestation [Pauli et al, 1981; Quan and Smith, 1973]. The similar embryologic timing of GS anomalies, like those found in the VATER association [Quan and Smith, 1973], suggests that the respective Anlagen share characteristics of cell biology, vascular supply, or topology during the critical period of injury. Thorough delineation of GS defects will increase our understanding of these relationships.

\section{REFERENCES}

Aleksic S, Budzilovich G, Reuben R, Laguna J, Finegold M, McCarthy J, Converse JM, Feigin I (1975): Unilateral arhinencephaly in Goldenhar-Gorlin syndrome. Dev Med Child Neurol 17:498504.

Cherstvoy ED, Laziuk GI, Lur'ye IV, Ostrovskaya TI (1978): The clinical and morphological features of the Goldenhar syndrome. Pediatriya 78:18-20.

Cohen MM Jr (1971): Variability versus "incidental findings" in the first and second branchial arch syndrome: Unilateral variants with anophthalmia. In Bergsma D (ed): Part XI. "Orofacial Structures." New York: Alan R. Liss, Inc., for The National Foundation-March of Dimes, BD: OAS VII(7): 103-108.

Feingold M, Baum J (1978): Goldenhar's syndrome. Am J Dis Child 132:136-138.

Goldenhar M (1952): Association malformatives de l'oeil et de l'oreille, en particulier le syndrome dermoide épibulbaire-appendices auriculaires-fistula auris congenita et ses rélations avec la dysostose mandibulofaciale. J Genet Hum 1:243-282.

Gorlin RJ, Jue KL, Jacobsen U, Goldschmidt E (1963): Oculoauriculovertebral syndrome. J Pediatr 63:991-999.

Gorlin RJ, Pindborg JJ, Cohen MM Jr (1976): Oculoauriculovertebral dysplasia. In "Syndromes of the Head and Neck." New York: McGraw-Hill, pp 546-552.

Grabb WC (1965): The first and second branchial arch syndrome. Plast Reconstr Surg 36:485-505.

Greenwood RD, Rosenthal A, Sommer A, Wolff G, Craenen J (1974): Cardiovascular malformations in oculoauriculovertebral dysplasia. J Pediatr 85:816-818.

Gupta JS, Gupta SD, Prashar SK (1968): Oculoauricular-cranial dysplasia. Br J Ophthalmol 52:346347. 
Herrmann J. Opitz JM (1969): A dominantly inherited first arch syndrome. In Bergsma (ed): Part II. "Malformation Syndromes." New York: Alan R. Liss, Inc., for The National FoundationMarch of Dimes, BD: OAS V (2):110-112.

Hodes ME, Gleiser S, DeRosa GP, Yune HY, Girod DS, Weaver DD, Palmer CG (1981): Trisomy 7 mosaicism and manifestations of Goldenhar syndrome with unilateral radial hypoplasia. J Craniofacial Genet Dev Biol 1:49-55.

Hollowich F, Verbeck B (1969): Zur Dysplasia oculauricularis (Franceschetti-Goldenhar syndrom). Klin Monatsbl Augenheilkd 154:430-433.

Kirkham TH (1971): Goldenhar's syndrome with inner ear defects. J Laryngol Othol 84:855-856.

Lamba PA, Ramamurthy S (1973): Oculoauriculovertebral dysplasia. Clin Pediatr 12:631-633.

Michaud C, Sheridan S (1974): Goldenhar's syndrome associated with cranial and neurological malformations. Can J Ophthalmol 9:347-350.

Murphy MJ, Risk WS, VanGilder JC (1980): Intracranial dermoid cyst in Goldenhar's syndrome. J Neurosurg 53:408-401.

Opitz JM, Faith GC (1969): Visceral anomalies in an infant with the Goldenhar syndrome. In Bergsma D (ed): Part II. "Malformation Syndromes." Baltimore: Williams and Wilkins, for the National Foundation-March of Dimes, BD: OAS V(2): 104-105.

Pashayan H, Pinsky L, Fraser FC (1970): Hemifacial microsomia-oculoverterbral dysplasia. J Med Genet 7:185-188.

Pauli RM, Graham JM Jr, Barr M Jr (1981): Agnathia, situs inversus, and associated malformations. Teratology 23:85-93.

Quan L, Smith DW (1973): The VATER association. J Pediatr 82:104-106.

Rapport RL, Dunn RC, Alhady F (1981): Anterior encephalocele. J Neurosurg 54:213-219.

Ross RB (1975): Lateral facial dysplasia. In Bergsma D (ed): "Morphogenesis and Malformation of Face and Brain." New York: Alan R. Liss, Inc., for the National Foundation-March of Dimes, BD:OAS XI(7):51-56

Setzer ES, Ruiz-Castaneda N, Severn C, Ryden S, Frias JL (1981): Etiologic heterogeneity in the oculoauriculovertebral syndrome. J Pediatr 98:88-90.

Shokeir MHK (1977): The Goldenhar syndrome: A natural history. In Bergsma D (ed): "Annual Review of Birth Defects, 1976: Natural History of Specific Birth Defects." New York: Alan R. Liss, Inc., for The National Foundation-March of Dimes, BD: OAS XIII (3C):67-83.

Smithells RW (1976): Oculoauriculovertebral syndrome. Dev Med Child Neurol 6:406-407.

Spranger J, Benirschke K, Hall JG, Lenz W, Lowry RB, Opitz JM, Pinsky L, Schwarzacher HG, Smith DW (1982): Errors of morphogenesis: Concepts and terms. J Pediatr 100:160-165.

Summitt RL (1969): Familial Goldenhar's syndrome. In Bergsma D (ed): Part II. "Malformation Syndromes." Baltimore: Williams and Wilkins for the National Foundation-March of Dimes, BD:OAS V (2): 106-109.

Thomas P (1980): Goldenhar Syndrome and hemifacial microsomia: Observations on three patients. Eur J Pediatr 133:287-292.

Edited by Jürgen Herrmann and John M. Opitz 